06

\title{
Дизайн градиентных композитных материалов на основе алюминия и графита методом центробежного литья
}

\author{
() Е.Д. Эйдельман, ${ }^{1,2}$ М.А. Дурнев ${ }^{1}$ \\ ${ }^{1}$ Санкт-Петербургская государственная химико-фармацевтическая академия, \\ 197376 Санкт-Петербург, Россия \\ ${ }^{2}$ Физико-технический институт им. А.Ф. Иофффе РАН, \\ 194021 Санкт-Петербург, Россия \\ e-mail: mad5245mail@gmail.com
}

(Поступило в Редакцию 26 октября 2017 г. В окончательной редакции 26 марта 2018 г.)

Предложен проверенный экспериментально метод центробежного литья для композитных материалов на основе $\mathrm{Al}$ с добавлением $\mathrm{Al}_{2} \mathrm{O}_{3}$ и С. Показано, что имеется возможность создания градиентов дополнительных материалов, например, для упрочнения поверхностного слоя. Указаны механизмы создания градиентов концентрации: первый - архимедова сила, второй - перераспределение зародышей по величине под действием вращения.

DOI: 10.21883/JTF.2018.11.46627.2531

\section{Введение}

Градиентные композиционные материалы (ГКМ) могут помочь в решении задач, возникающих при проектировании конструкций, предназначенных для работы в экстремальных условиях [1,2]. Перспективным методом получения ГКМ является центробежное литье, особенно для материалов на основе алюминия [3].

ГМК отличаются от традиционных изотропных композитных материалов наличием пространственно-неоднородных структур, благодаря которым они приобретают новые свойства и новые функции. Поиск и разработка новых технологических процессов синтеза ГКМ и моделирование их технологии получения, определяемой параметрами нагружения, представляют собой весьма актуальную задачу.

Центробежное литье, как способ изготовления анизотропных структур, известен (см., например, [4,5]), однако возможность получения заданной технологии наполнителя в дисперсно-наполненных композитных материалах и влияние градиента распределения наполнителя на работоспособность литых ГКМ остаются неизученными.

Метод центробежного литья опробован для получения ГКМ на базе алюминиевых сплавов, армированных керамическими частицами различной природы и состава. Поверхностные слои с повышенной концентрацией армирующей фазы предполагается организовать за счет направленного перемещения дисперсных частиц в жидкометаллической суспензии.

Для успешной технологии получения ГКМ необходимо понимание механизмов, приводящих к экспериментально наблюдаемым свойствам. К сожалению, в работах, посвященных методам технологии, этому уделяется недостаточно внимания.

Рассмотрение процессов, происходящих при центробежном литье, должно опираться на теорию фазовых переходов первого рода и, в частности, на теорию кристаллизации. Теория фазовых переходов первого рода хорошо известна [6,7], хотя и развита на примере перехода пар-жидкость. Эта теория находит самые разнообразные применения. Например, наиболее близкие к теме настоящей работы о переходах в твердое состояние - это изучение формирования эпитаксиальных структур [8,9].

Во всех работах по теории фазовых переходов первого рода важнейшей задачей является построение распределения зародышей по размерам непосредственно перед окончанием перехода в так называемой области глубокой закритичности. Все построения при этом ограничиваются анализом диффузионного движения зародышей малого размера. Это верно пока переход происходит из газовой фазы.

При переходе из жидкой фазы при кристаллизации, в частности при центробежном литье, необходимо учитывать макроскопическое движение малых зародышей в метастабильном состоянии, т.е. наличие течений. Это могут быть, например, конвективные течения [10]. В весьма грубом приближении можно ограничиться рассмотрением движений-течений, вызванных силами вязкости и архимедовой силой, например, при больших скоростях вращения.

В настоящей работе общие задачи технологии получения ГКМ будут решаться на примере материалов на основе алюминия. Основным материалом будет сплав АК12. Дополнительными материалами будут оксид алюминия $\mathrm{Al}_{2} \mathrm{O}_{3}$ и частицы графита - С. Общим результатом будет построение распределения закритических зародышей для двух компонент дополнительного материала.

\section{1. Эксперимент}

В качестве основного материала использовался сплав АК12, имеющий в жидком состоянии плотность 

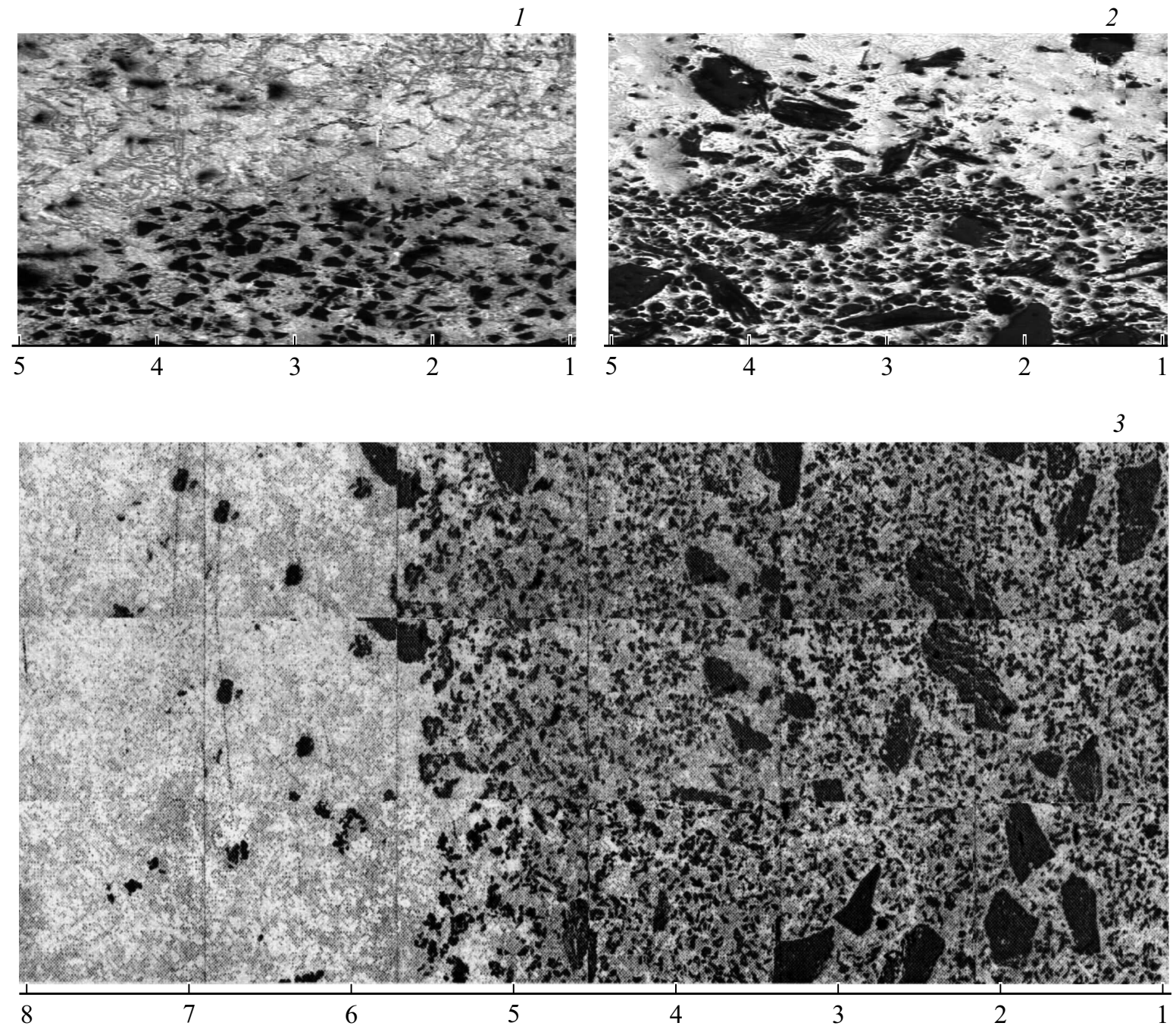

Рис. 1. Микроструктура образцов: $1-\mathrm{AK} 12+10 \% \mathrm{Al}_{2} \mathrm{O}_{3} ; 2-\mathrm{AK} 12+2 \% \mathrm{Al}_{2} \mathrm{O}_{3}+3 \% \mathrm{C} ; 3-\mathrm{AK} 12+10 \% \mathrm{Al}_{2} \mathrm{O}_{3}+2 \% \mathrm{C}$. Темные области - армирующий дополнительный материал. Справа налево отложено расстояние от наружной стенки в миллиметрах.

Типы использованных образцов

\begin{tabular}{c|l}
\hline № & \multicolumn{1}{|c}{ Состав } \\
\hline 1 & $\mathrm{AK} 12-10 \% \mathrm{Al}_{2} \mathrm{O}_{3}$ (средний размер частиц $D_{\text {med }}-$ \\
2 & $40 \mu \mathrm{m}$ \\
3 & $\mathrm{AK} 12+2 \% \mathrm{Al}_{2} \mathrm{O}_{3}+3 \%$ \\
4 & $\mathrm{AK} 12+10 \% \mathrm{Al}_{2} \mathrm{O}_{3}+2 \%$ \\
& $200-400 \mu \mathrm{m}$
\end{tabular}

$\rho_{\mathrm{Al}} \approx 2.67 \mathrm{~g} / \mathrm{cm}^{3}$. В качестве дополнительных материалов использовались $\mathrm{Al}_{2} \mathrm{O}_{3}$, имеющий плотность $\rho_{\mathrm{Al}_{2} \mathrm{O}_{3}} \approx$ $\approx 4.00 \mathrm{~g} / \mathrm{cm}^{3}$, и графит плотностью $\rho_{\mathrm{C}}=1.70 \mathrm{~g} / \mathrm{cm}^{3}$. Использовались четыре типа образцов, данные о составе которых приведены в таблице.

Образцы изготавливались в одинаковых условиях с температурой оснастки $T=210 \pm 10^{\circ} \mathrm{C}$ и температурой расплава $T=750 \pm 10^{\circ} \mathrm{C}$ методом центробежно- го литья при угловой скорости $\omega=40 \pi \mathrm{rad} / \mathrm{s}$ и имели форму полых цилиндров с расстоянием $r$ до оси $\sim 60 \mathrm{~mm} \leq r \leq 92-94 \mathrm{~mm}$ и высотой 60-90 mm. Разрезанные на сектора цилиндры исследовались на микроскопе Leica c наружной и внутренней стороны боковой поверхности.

Типичные результаты микроскопических исследований трех первых типов образцов представлены на рис. 1. Нумерация совпадает с нумерацией образцов в таблице.

Измерена твердость образцов при помощи ультразвукового твердомера МЕТ-У1 (ТУ 4271-001-18606393-00).

Установлено, что частицы графита не повышают твердости ГКМ по сравнению с исходным АК12. Введение частиц $\mathrm{Al}_{2} \mathrm{O}_{3}$ повышает твердость в поверхностных слоях более чем на 100 у.е., до 430-464 у.е.

Был проведен пересчет в долю армирующих частиц. Распределение представлено на рис. 2.

Выявлено, что ширина градиентных слоев и распределение частиц в этих слоях меняются с изменением 

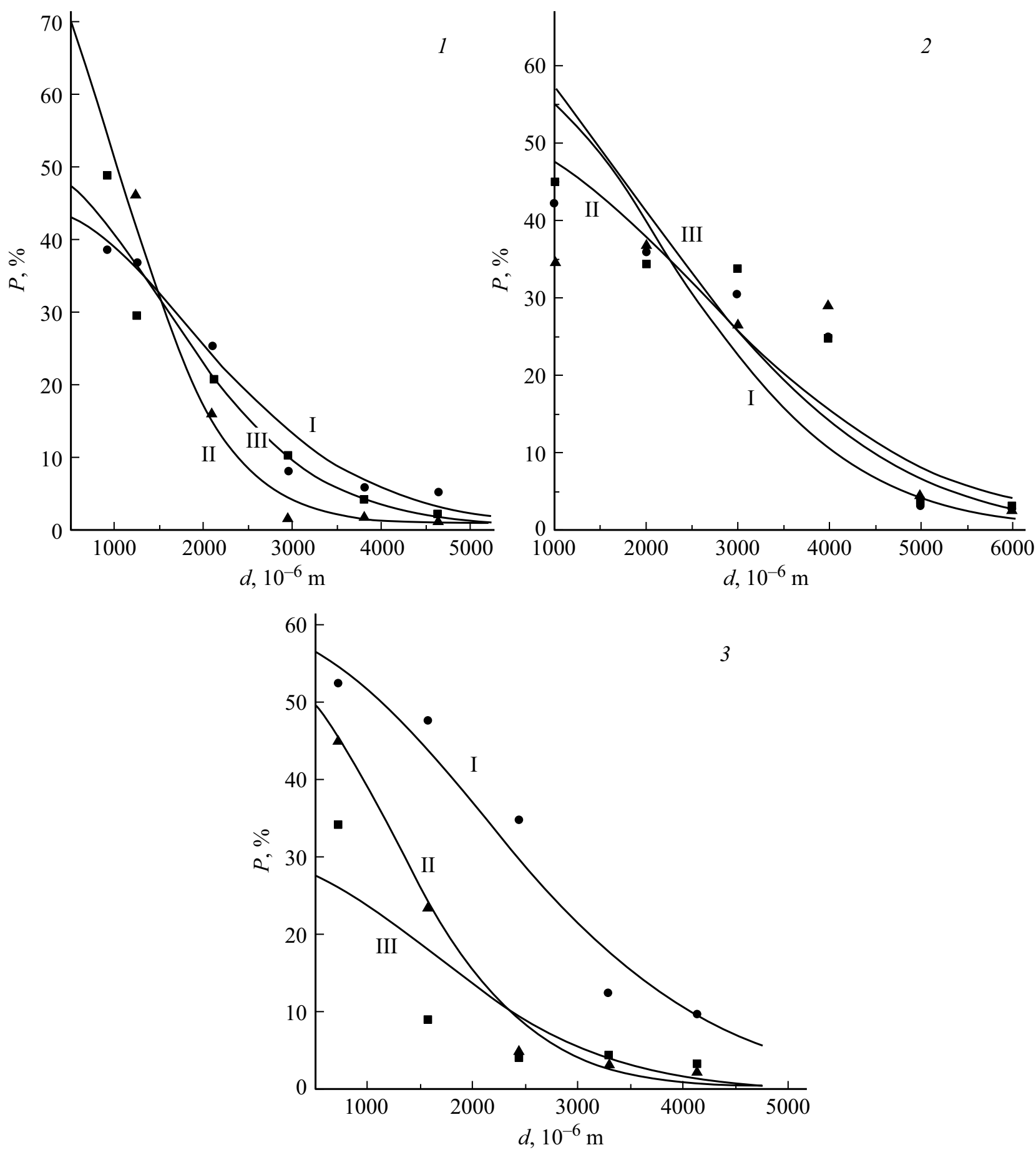

Рис. 2. Распределение армирующих частиц в образцах градиентных композиционных материалов: $1-\mathrm{AK}_{12}+10 \% \mathrm{Al}_{2} \mathrm{O}_{3} ; 2-$ $\mathrm{AK} 12+2 \% \mathrm{Al}_{2} \mathrm{O}_{3}+3 \% \mathrm{C} ; 3$ - АК12 + 10I, II, III - верх, середина и нижняя часть цилиндра соответственно.

удельного веса частиц, а также по высоте втулок. В образцах 1 в верхней части цилиндра содержание частиц $\mathrm{Al}_{2} \mathrm{O}_{3}$ заметно меньше, чем в центральной и нижней частях. В армированных двумя дополнительными материалами образцах 2 и 3 градиентный слой формируется более заметно в образце 3 , содержание частиц $\mathrm{Al}_{2} \mathrm{O}_{3}$ в котором в 5 раз больше. Распределение частиц по высоте примерно одинаково, всплыванию графита препятствуют частицы $\mathrm{Al}_{2} \mathrm{O}_{3}$. В образцах 4, армированных только графитовыми частицами (10\% по весу), градиентный слой не обнаружен. В верхней части цилиндра наблюдается возрастание объемной доли графита, а в нижней части ее снижение. Это можно объяснить, во-первых, величиной и объемным содержанием частиц, а также тем, что плотность частиц графита меньше, чем алюминия, что влечет за собой снижение центробежной силы. 


\section{2. Обсуждение и модель}

\section{1. Технология получения на основе действия архимедовой силы}

Очевидно, что перемещение дисперсных частиц в поле действия центробежных сил определяется их плотностью. Твердые дисперсные частицы, имеющие плотность, большую, чем матричный алюминиевый сплав, перемещаются к наружной стенке формы (изложницы), менее плотные - к оси вращения, на свободную поверхность (во внутреннюю часть отливки).

Соответствующая закону Архимеда $\left(\rho_{p}-\rho_{f}\right) g V$ сила для вращающейся системы выразится уравнением

$$
F=\omega^{2} \operatorname{Vr}\left(\rho_{p}-\rho_{f}\right),
$$

где $F$ - центробежная сила, действующая на частицу; $\rho_{p}$ и $\rho_{f}-$ соответственно плотность частицы и жидкого металла; $g$ - ускорение свободного падения; $V$ объем дисперсной частицы; $r-$ расстояние от оси вращения, совпадающее с радиусом центра сил инерции частицы и равный ему радиус центра сил инерции вытесненного объема жидкого металла; $\omega-$ угловая скорость вращения.

Из формулы (1) видно, что силы, действующие на частицу, погруженную во вращающийся расплав, возрастают в $\omega^{2} r / g$ раз. Видно также, что сила, действующая на частицы при центробежном литье, увеличивается с увеличением плотности частиц, помещенных в расплав.

Отсюда следует, что подъемная сила частиц графита объясняет их всплывание и перемещение к свободной внутренней поверхности при вращении жидкого расплава.

Подъемная сила частиц $\mathrm{Al}_{2} \mathrm{O}_{3}$ по аналогичным причинам приводит к их перемещению к внешней поверхности. Отсюда следует, что варьирование весовых соотношений $\mathrm{C} / \mathrm{Al}_{2} \mathrm{O}_{3}$ позволяет регулировать концентрацию армирующих частиц около нужной поверхности и создавать ГКМ с заданной твердостью у нужной для эксплуатации поверхности.

\section{2. Технология получения на основе распределения армирующих частиц}

Наибольшей силой, действующей на твердые большие закритические зародыши, образующиеся вокруг частиц дополнительных армирующих материалов, является сила вязкого трения Стокса $6 \pi \eta R_{i} v_{i}$. Коэффициент вязкости в АК12 в расплавленном состоянии $\eta \approx 0.32 \mathrm{~Pa} \cdot \mathrm{s}$; $v_{i}$ и $R_{i}$ - соответственно скорость и размер закритического зародыша $\mathrm{Al}_{2} \mathrm{O}_{3}(i=1)$ и частицы графита $\mathrm{C}$ $(i=2)$. В соответствии с данными, приведенными в таблице, $R_{1}=20 \mu \mathrm{m} ; R_{2}=100-200 \mu \mathrm{m}$.

Легко найти, что начальная скорость вращения $\omega r$ затухает со временем $t$ по закону

$$
v_{i}=\omega r \exp \left(-\frac{9 \eta}{2 \rho_{M} R_{i}^{2}}\right) .
$$

Именно эти скорости заменяют среднеквадратичную скорость движения малых зародышей при отсутствии макроскопического течения.

Из картины нуклеации очевидно, что вероятность поглощения малого зародыша большим пропорциональна коэффициенту диффузии $D_{i}=C_{i} v_{i} S_{i} / R_{i}$, где кроме уже определенных величин введена площадь поверхности большого зародыша соответствующего сорта $S_{i}$. Постоянные $C_{i}$ - коэффициенты пропорциональности величины порядка единиц. С другой стороны, из соображений размерности (см., например, [6]) следует, что

$$
D=C_{1} n_{1} v_{1} \frac{S_{1}}{R_{1}}+C_{2} n_{2} v_{2} \frac{S_{2}}{R_{2}}
$$

Величина $n_{i}$ - численная доля большого зародыша соответствующего сорта. При наличии течения именно скорость течения становится основной составляющей относительной скорости движения большого и малого зародышей. Такая скорость по порядку величины совпадает с $v_{i}$.

В случае возбуждения конвективного движения скорость течения пропорциональна корню из „надкритичности“, т.е. превышения числом, например, числом Рэлея, определяющим конвекцию, того критического значения, при котором конвекция возбуждается. Отметим, впрочем, что вращение подавляет конвекцию [10]. При вращении большие зародыши стремятся перейти к движению со скоростями $v_{i}$.

Кристаллизация [6,7] происходит в основном на центрах конденсации, образующихся вокруг частиц дополнительного материала. На закритической стадии в отсутствии макроскопических движений метастабильного материала распределение закритических зародышей по размерам $v_{i}$ найдено в [7].

Имеем:

$$
G \cong \Theta(t) \frac{1}{\sqrt{D t}} \exp \left(-\frac{\left(d_{1}-d_{1}^{0}\right)^{2}+\left(d_{2}-d_{2}^{0}\right)^{2}}{4 D t}\right) .
$$

Степень закритичности $d_{i}-d_{i}^{0}$ определяет отклонение размера $d_{i}$ большого зародыша соответствующего сорта от размера критического зародыша $d_{i}^{0}$ того же сорта. В условиях большей закритичности $d_{i} \gg d_{i}^{0}$. Величина $\Theta(t)$ - амплитуда, не зависящая от размеров зародыша.

В соответствии с этим распределением, но при замене коэффициента диффузии на величину (3), определяемую наличием течения, проведены сплошные линии на рис. 2.

Распределение (4) является функцией Грина кинетического уравнения, задающего рост зародышей [6,7]. Для получения распределения $\mathrm{P}$ зародышей армирующих материалов $\mathrm{Al}_{2} \mathrm{O}_{3}$ и $\mathrm{C}$ в образце, в нее нужно подставить время фазового перехода $t_{f}$, которое гораздо меньше характерного времени затухания $4 \pi_{M} R_{i}^{2} /(9 \eta)$ и подставить в (4) величину $D$, которая определяется течением в соответствии с формулой (3).

Можно считать, что именно частицы армирующих материалов являются зародышами и их распределение 
по материалу образца после кристаллизации (рис. 1) отражает распределение закритических зародышей перед фазовым переходом. Во время фазового перехода зародыши растут, и их рост ограничен только размером расплава. При сильном вращении центробежные силы способствуют росту преимущественно в направлении от оси вращения к изложнице. Отсюда следует, что размер зародыша $d$ превращается в расстояние от положения зародыша до внешней границы расплава.

Запишем распределение закритических зародышей перед фазовым переходом в зависимости от расстояния $x_{i}$, отсчитанного от внешней стенки образца или, что то же самое, от изложницы. Имеем

$$
P\left(x_{1} ; x_{2}\right)=\frac{B}{\sqrt{D t_{f}}} \exp \left(-\frac{x_{1}^{2}+x_{2}^{2}}{4 D t_{f}}\right) .
$$

Эта формула включает параметр $B$, зависящий от сил плавучести.

К сожалению, результаты эксперимента (рис. 1) не позволяют разделить положения примесей частиц графита и примесей $\mathrm{Al}_{2} \mathrm{O}_{3}$. Поэтому функция совместного распределения для двух видов (индекс $i=1 ; 2$ ) армирующих частиц должна быть представлена в виде

$$
P(x)=A_{1} \exp \left(-\frac{x^{2}}{4 \sigma_{1}^{2}}\right)+A_{2} \exp \left(-\frac{x^{2}}{4 \sigma_{2}^{2}}\right) .
$$

Здесь $A_{i}$ - амплитуды, которые имеют вид

$$
A_{i}=\frac{B_{i}}{\sqrt{\omega r R_{i} t_{f}}} \exp \left(-\frac{9 \eta_{i}}{8 \rho_{M} R_{i}^{2}} t_{f}\right) .
$$

Среднеквадратичное отклонение в распределении

$$
\sigma_{i}=\sqrt{\omega r R_{i} t_{f}} \exp \left(-\frac{9 \eta_{i}}{8 \rho_{M} R_{i}^{2}} t_{f}\right)
$$

можно считать независящими от архимедовой силы. С другой стороны, из-за того что плотность графитовых частиц гораздо меньше плотности частиц оксида алюминия, $B_{1} \gg B_{2}$. Величины $C_{i}$ из (3) включены в величину $t_{f}$, определенную наиболее грубо.

Важно, что расчетное распределение (вероятность) крупных зародышей армирующих материалов, полученное по формулам (6)-(8) и представленное на рис. 2 в виде сплошной линии, хорошо совпадает с экспериментальными результатами, полученными в результате обработки непосредственных микроскопических наблюдений по рис. 1.

\section{Вывод}

Показано, что с помощью подбора дополнительных армирующих материалов, имеющих плотности больше и меньше, чем основной материал, можно создавать ГКМ с заданной твердостью методом центробежного литья.

Этот практический вывод основан на рассмотрении модели действия архимедовой силы и предсказаний по распределению армирующих материалов.

\section{Благодарности}

Е.Д. Эйдельман благодарит за поддержку Российский научный фонд (проект 16-19-00075).

\section{Список литературы}

[1] Хейбеи, М.Л. Проектирование процессов комбинированной обработки. М.: Машиностроение, 2005. 272 с.

[2] Горелик С.С., Дашевский М.Я. Материаловедение полупроводников и диэлектриков. М.: МИСИС, 2003. 480 с.

[3] Durnev M.A., Eidelman E.D. // Nanosystems: Physics, Chemistry, Mathematics. 2017. Vol. 8. N 3. P. 360-364.

[4] Kevorkijan V. // American Ceramic Society Bulletin. 2003. Vol. 82. N 2. P. 60-64.

[5] Анисимов О.В., Штанкин Ю.В. // Перспективные материалы. 2010. № 2. С. 5-10.

[6] Kurasov V.B. Advances in the First Order Phase Transitions. SPb.: VVM Publishing Ltd., 2014. N 321. P. II. 319 p.

[7] Курасов В.Б. // Письма в ЖТФ. 2015. Т. 41. Вып. 7. C. 89-95.

[8] Дубровский В.Г. Теория формирования эпитаксиальных наноструктур. М.: Физматлит, 2009. 352 с.

[9] Казанский М.А., Назаренко М.В., Дубровский В.Г. // Письма в ЖТФ. 2011. Т. 37. Вып. 6. С. 78-87.

[10] Эйдельман Е.Д. // УФН. 1995. Т. 165. С. 1279-1294. 